\title{
ضبط قواعد الحذر في البنوك الجزائرية وفث المعايير الاحترازية الدولية
}

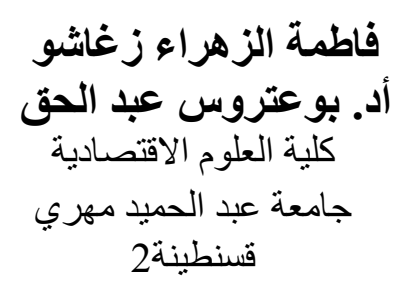

في ظل تصاعد المخاطر المصرفية بفعل احتدام المنافسة

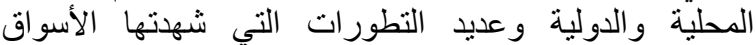
العالمية، كان لزاما التفكير في إيجاد آليات تكفل الإدارة التهابة الرشيدة

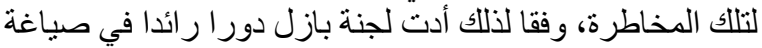

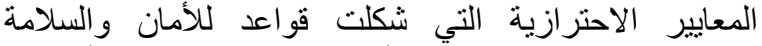

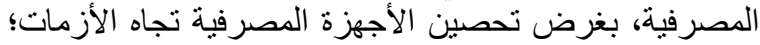

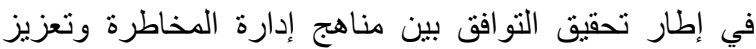

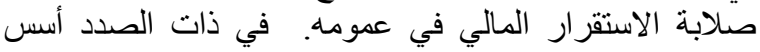

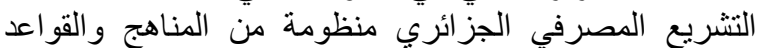

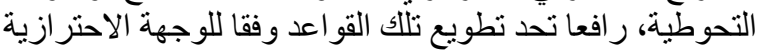

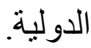

الكلمات المفتاحية: اتفاقيات بازل، المعايير الاحترازية، البنوك

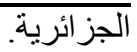

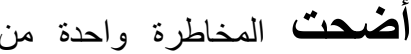

أبجديات الصناعة المصرفية وكأنها

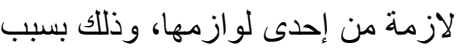

حالة عدم التأكد المصناحبة لوازمها، للوضعية

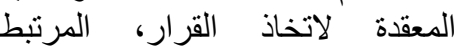

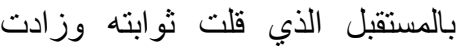

متغير اته حتى كاد يكون الثابت الوحيد

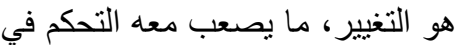

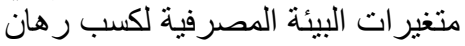
البقاء في السوق، ويبعث على بلى بحث رهثة رشد إدارة تلك المخاطرة وتضينيق ونيق نطاقها إلى أدنى المستويات المدكنة. وهو ما تجلى من خلال اتفاقيات بازل التهل

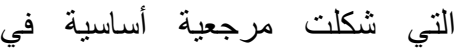
صياغة القواعد الضـابطة لإدارة المخاطرة المصرفية.

\begin{abstract}
:
In light of the escalating banking risks due to the Intensity of local and international competition and the many developments in world markets, it was necessary to consider mechanisms to ensure the rational management of this risk. Accordingly, the Basel Committee has played a leading role in the formation of the preventive standards that constitute the rules of bank safety and security; for the purpose of fortifying banking systems against crises in the context of achieving compatibility between risk management approaches and enhancing the solidity of financial stability in general. In this regard, the Algerian banking legislation established a system of precautionary rules, raising the challenge of adapting these rules according to the international precautionary approach.
\end{abstract}

Keywords: Basel Conventions, prudential standards, Algerian banks. 


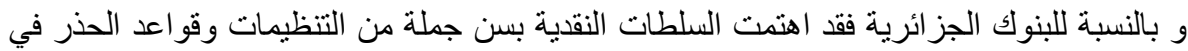

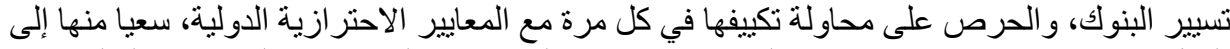

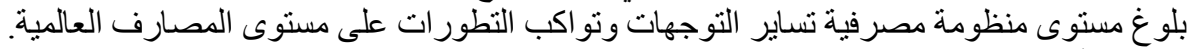

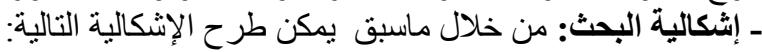

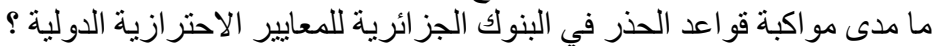

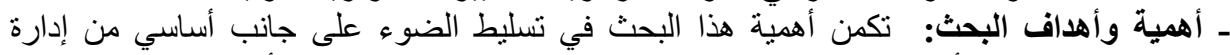

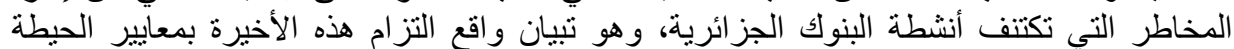

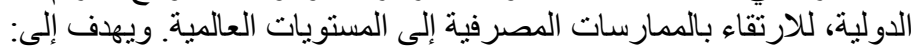
-

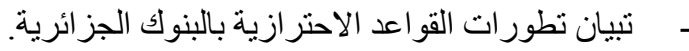

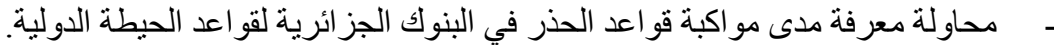

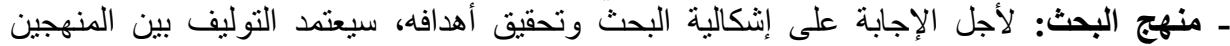

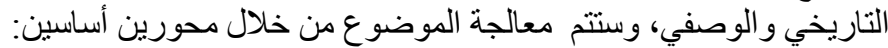

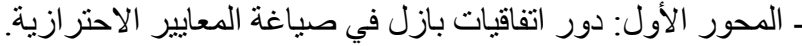
المحور الثاني: واقع التزام البنوك الجزائرية بالمعايير الاحترازية الدولية.

المحور الأول: دور اتفاقيات بازل في صياغة المعاييز الاحترازية

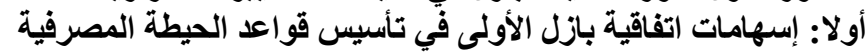

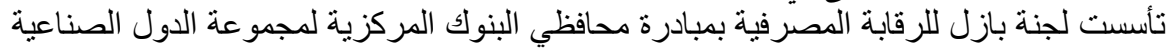

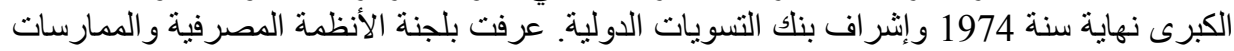

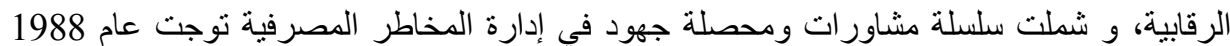
باتفاق اكتسى الصبغة العالمية.

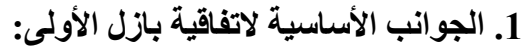

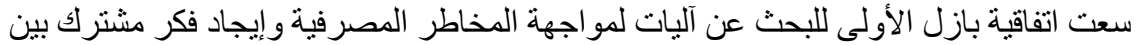

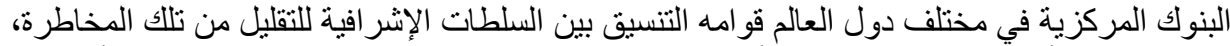

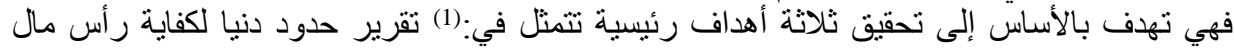

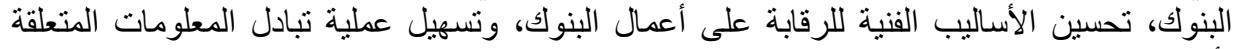

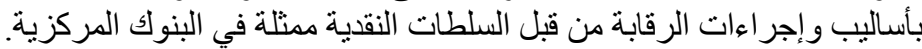
أ. مكونات الإطار الجديد لكفاية رأس المال المات المصرفي:

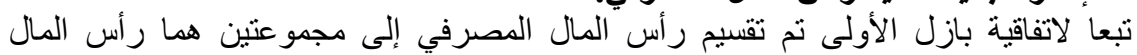

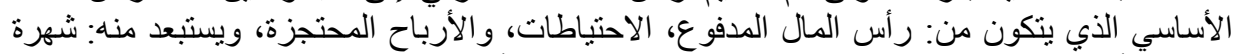

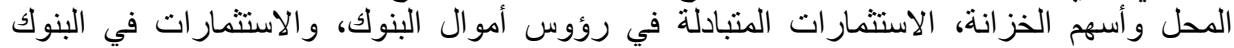

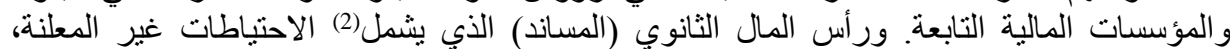

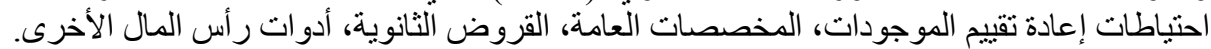
ب. قياس كفاية رأس المال (الملاءة المصرفيمة المصنة):

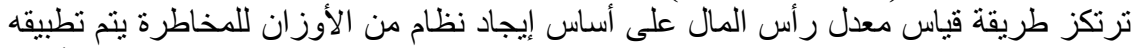

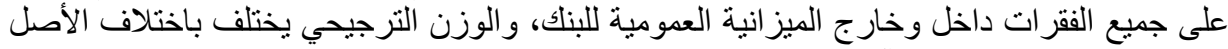

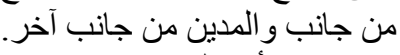

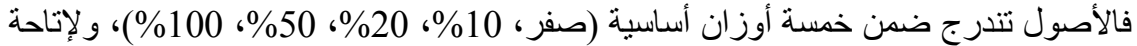

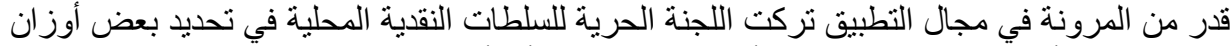
المخاطر. كما أن إعطاء وزن مخاطر لأصل ما لا يستلزم أنه أصل مشكوك في تحصيله بذات الدئ لدرجة، 
و إنما هو أسلوب ترجيحي للتفرقة بين أصل وآخر حسب درجة المخاطرة بعد تكوين المخصصات

اعتمدت لجنة بازل معيار كوك ليكون ملزما لجالجيع البنوك كمعيار دولي وكدلالة على متانة المركز

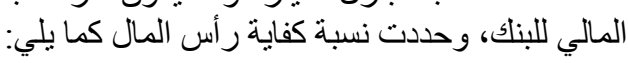

$\% 8 \leq$

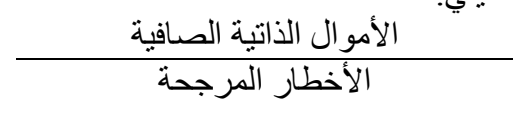$$
\text { نسبة كفاية رأس المال = }
$$

\section{2. التعديلات في معيار كفاية رأس مال بازلآ:}

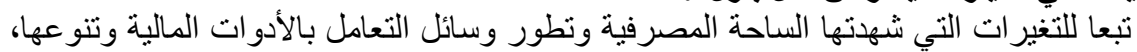

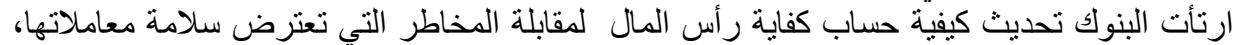

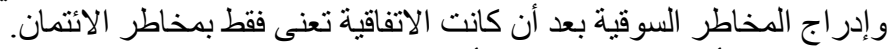

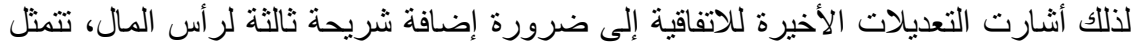

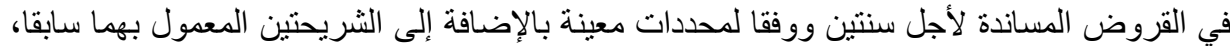

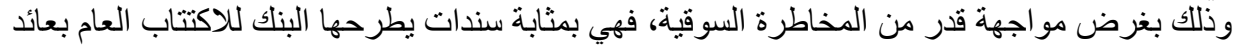

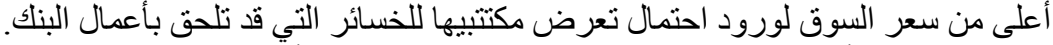

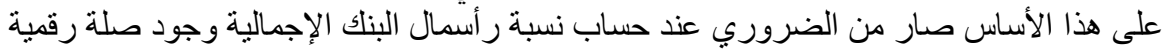

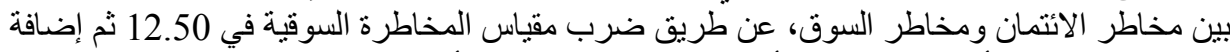

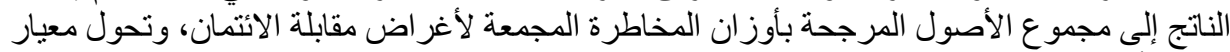

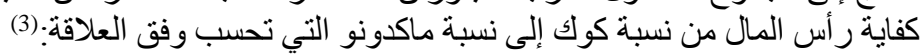

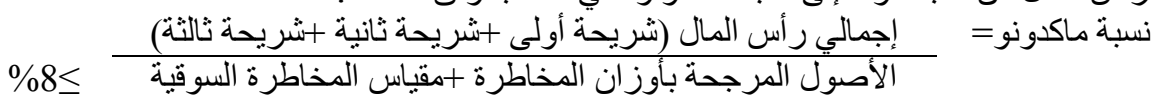
12.50×

في هذا الصدد طرحت اللجنة طرقا إحصائية ومقاييس كمية ونوعية نمطية لقياس هذه المخاطرة والتي يمكن إير ادها على النحو التالي: الطريقة المعيارية: تقوم هذه الطريقة على تلى تحليل كلا الخطرين: الخطر الخاص

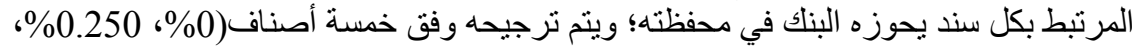
0.001\%، 0.601\%، 8\%). والخطر العام الذي تتعرض له المحفظة ككل، ويتم تقديره وفقا

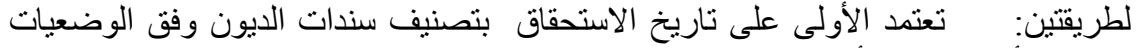

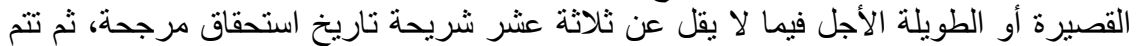

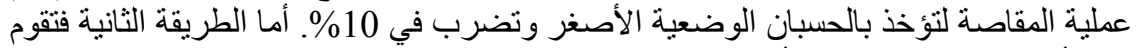

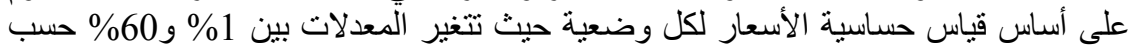

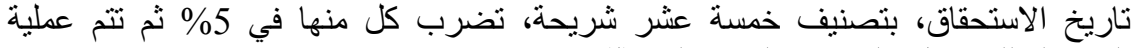

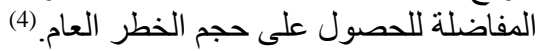
• طريقة النماذج الاخلية: تضفمن هذه الطريقة نماذج إحصائية متطورة، تعتمدها

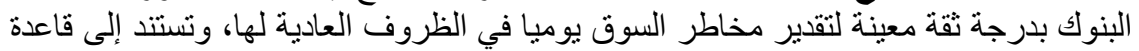

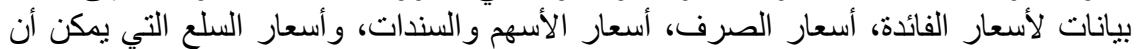

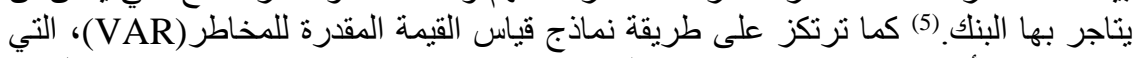

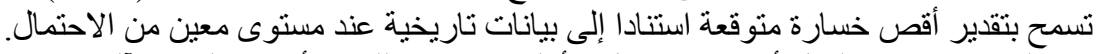

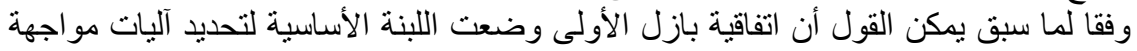

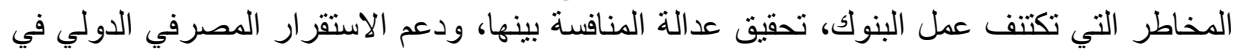

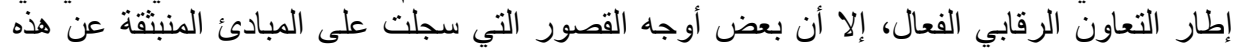




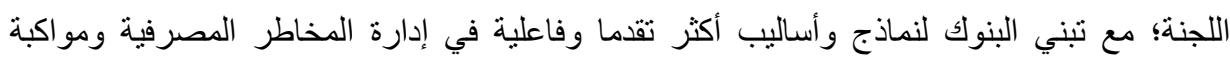
اللتطور الهائل و المعلوماتية؛ كل ذللك مهد لميلاد اتفاقية جديدة تعرف باتية فاتفاقية بازل الثانية الثانية.

ثنانيا: اتفاقية بازل الثانية

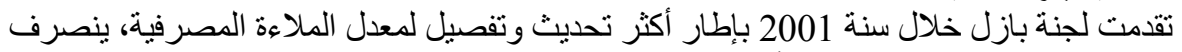

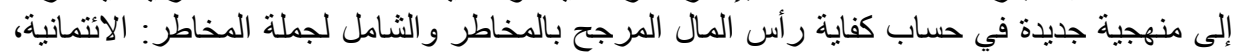

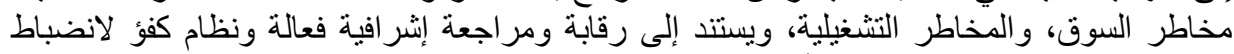
السوق و استقر اره وفق ركائز ثلاث أساسية:

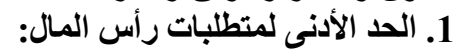

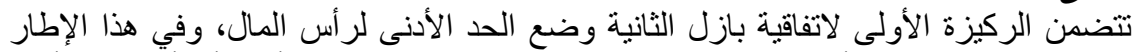

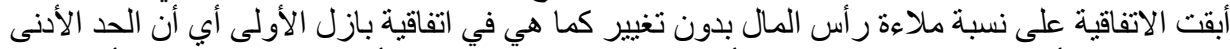

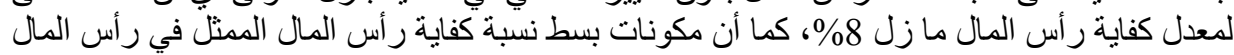

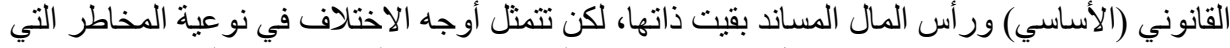

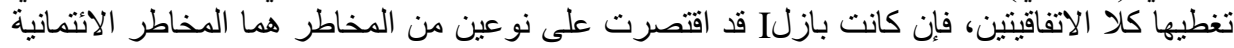

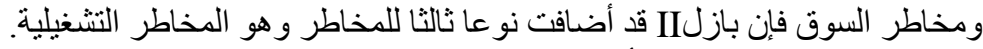

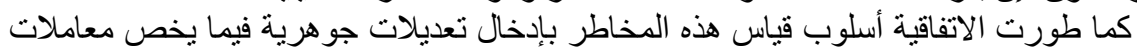

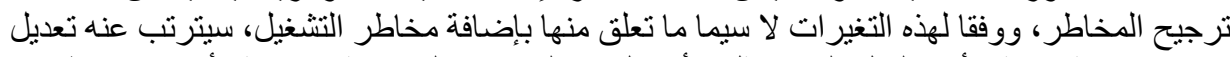

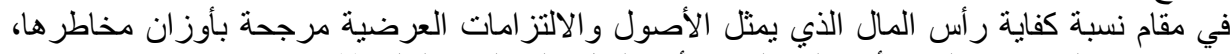

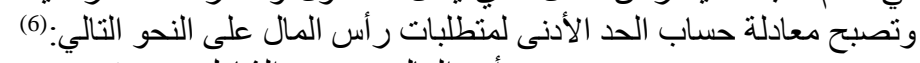

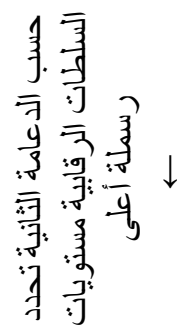
رأس المال بمفهو مه الثنامل بنفس تعريف النقالف

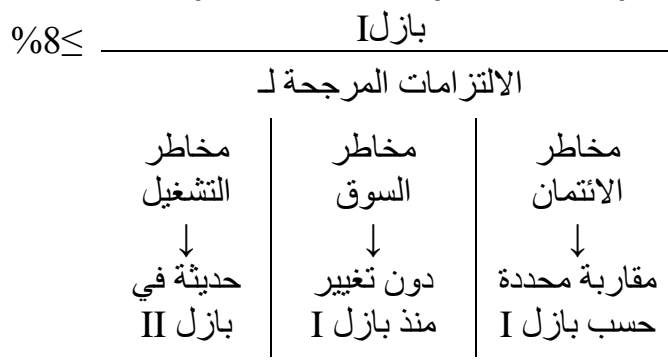

نسبة كفاية رأس المال

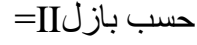

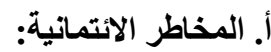

تطرح الاتفاقية منهجين أساسيين: الأول المنهج المعياري و الثاني منهج للتصنيف الداخلي.

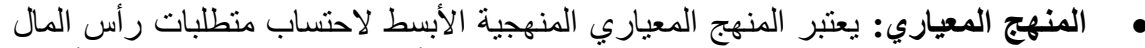

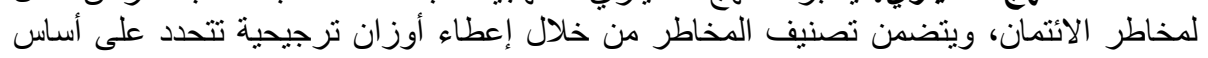

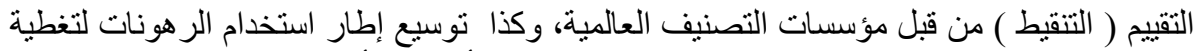
المخاطر الايتمانية وتحديد وسائل تخفيفها وباتلاتلالي تخفيف الأعباء الر أسمالية.

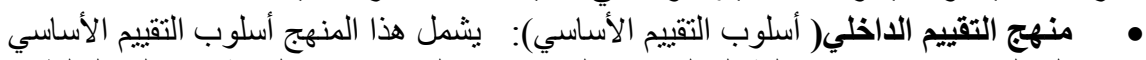

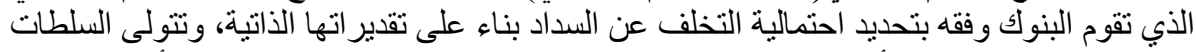

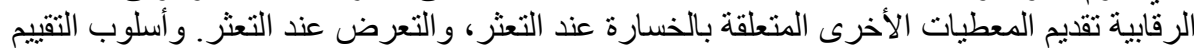

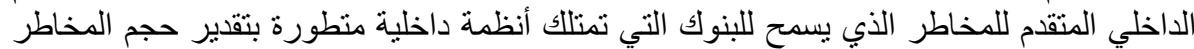

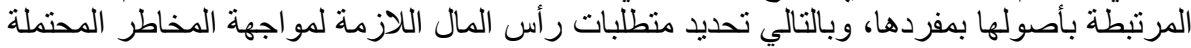

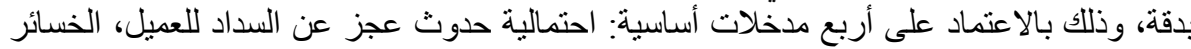

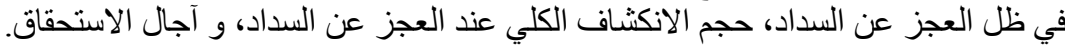


حددت اتفاقية بازل الثلاث مناهج يمكن للبنوك اعتمادها لقياس منطلبات رأس المال: منهج

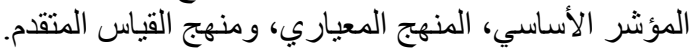

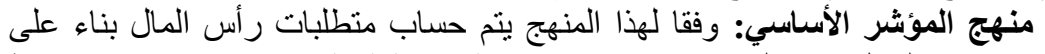

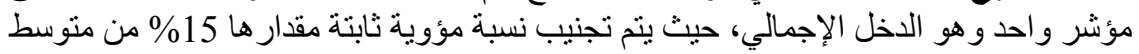

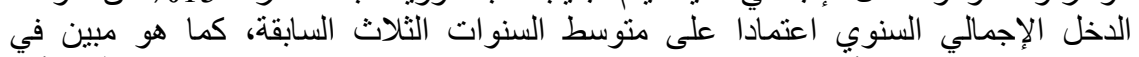

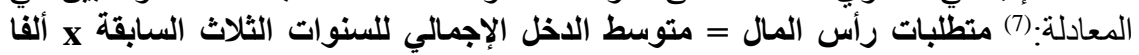

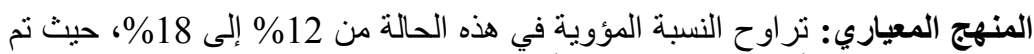

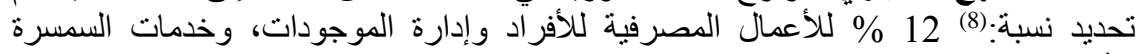

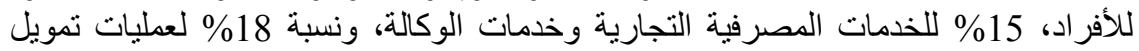

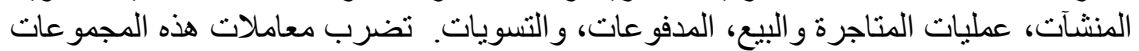

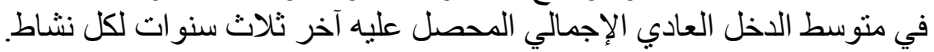

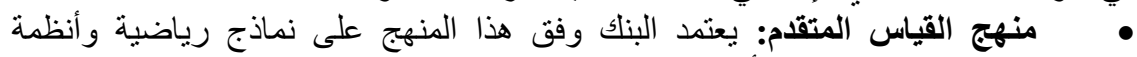

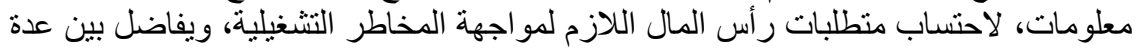
طرق منها: منهج القياس الداخلي، منهج توزيع الخسائر ، وطريقة بطاقة الأداء المنو ازنة.

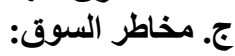
نم الإبقاء على الطريقتين المعيارية وطريقة النماذج الداخلية، أب أنه لم يطرأ أي تعديل على

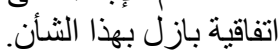

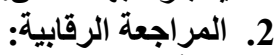

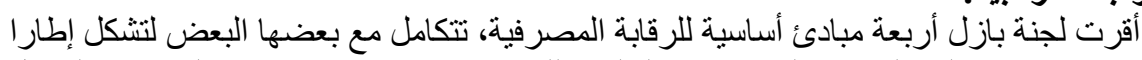

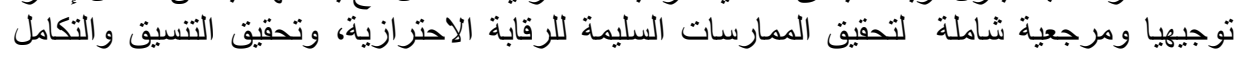
المطلوبين على مستوى الهيئات الرقابية.

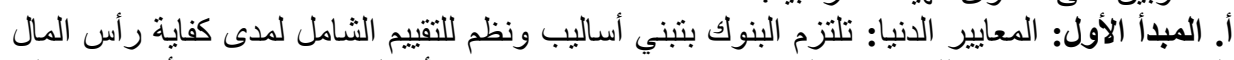

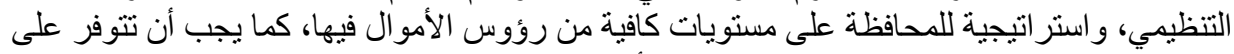

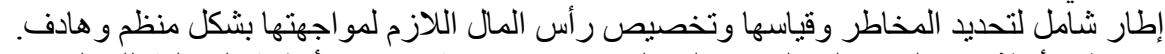

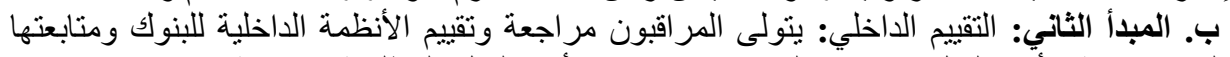

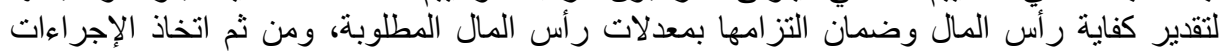

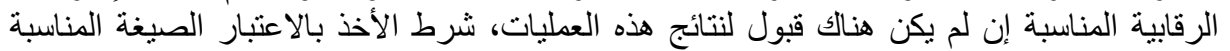
وحجم ودرجة تطور كل بنكانك.

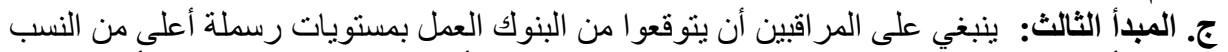

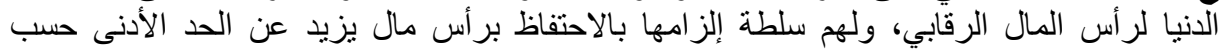

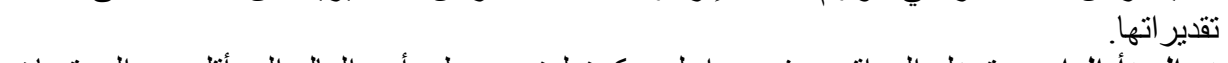

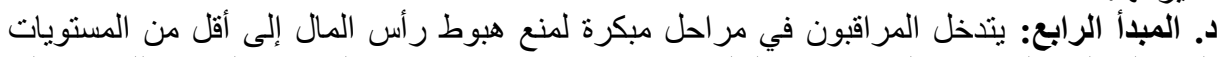

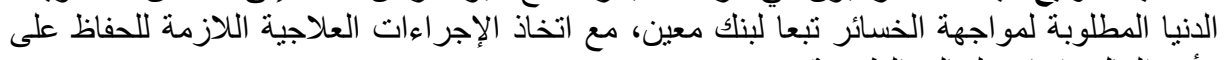
رأس المال و إعادته لحالته الطبيعية.

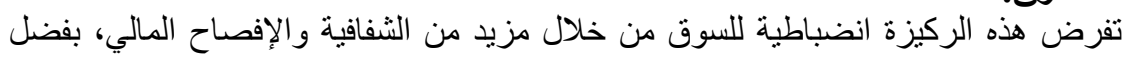
3. - 3 انضباط السوق:

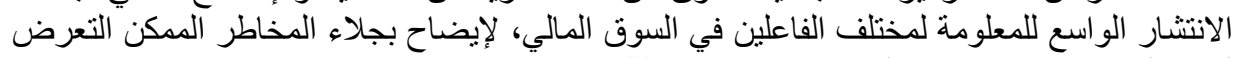

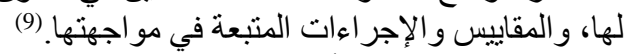

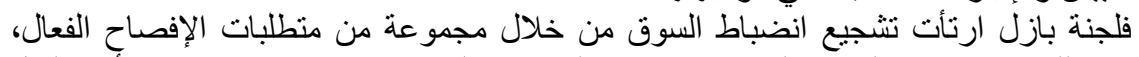

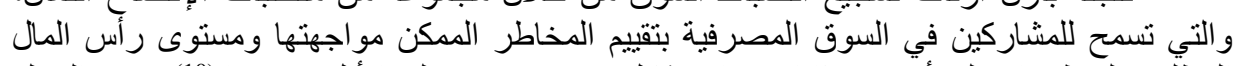

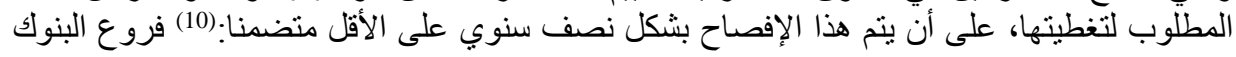


الثاملة الخاضعة للمعايير الاحترازية لاتفاقية بازلII والإجراءات المطبقة على الفروع غير الملتزمة

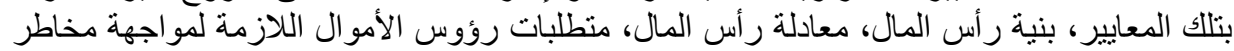

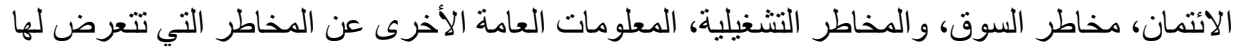

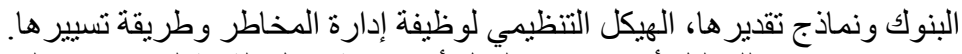

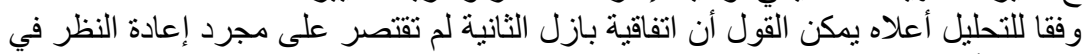

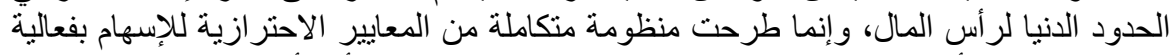

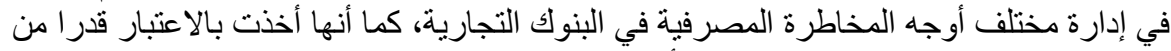
الاختلاف في بيئة العمل المصرفي، وأتاحت جملة من الخيارات للارتئة التقاء بإدارة المخاطرة

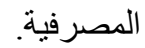

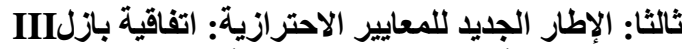

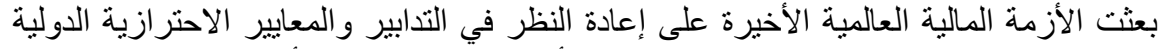

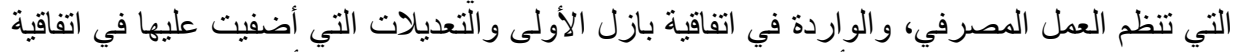

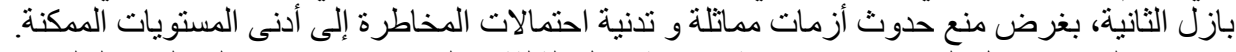

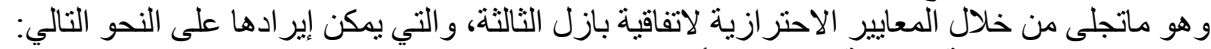

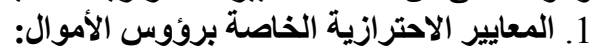

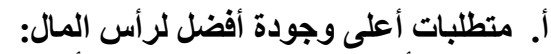

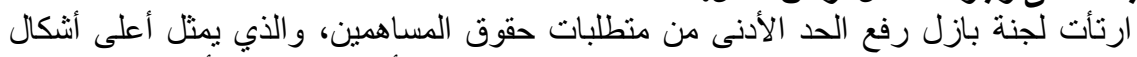

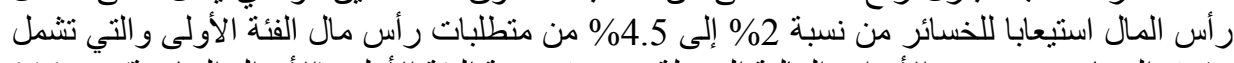

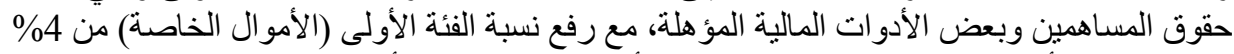

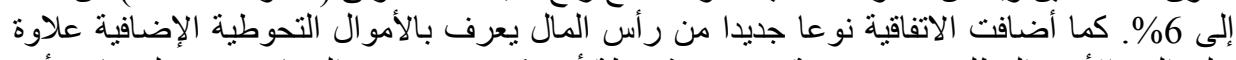

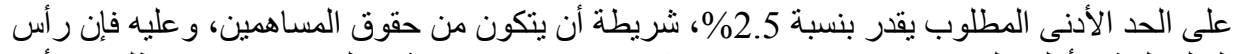

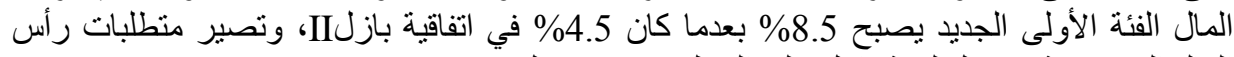

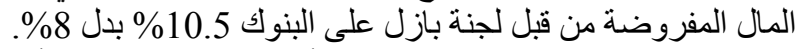

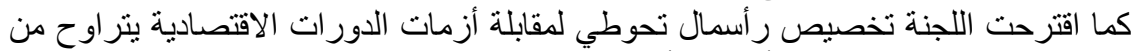

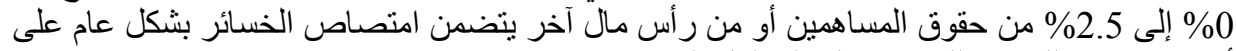
أن يتم تطبيق ذللك وفقا للظروف المحلية لكل بلد. (11)

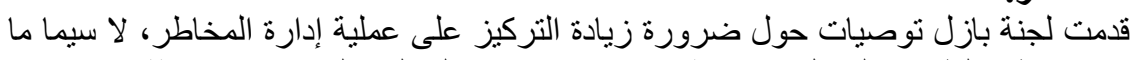

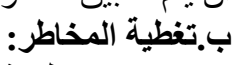

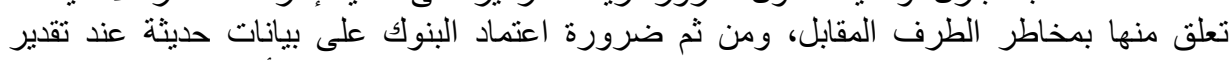

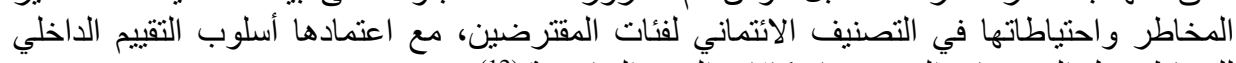

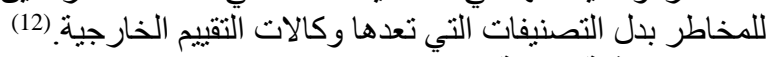

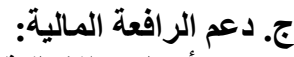

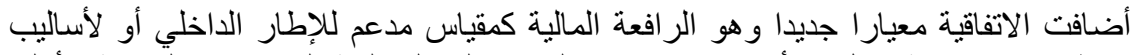

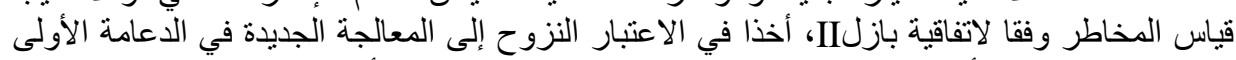

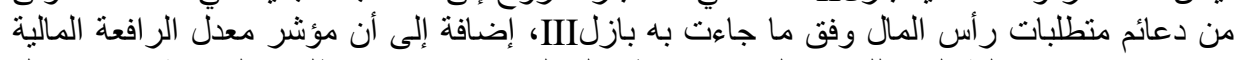

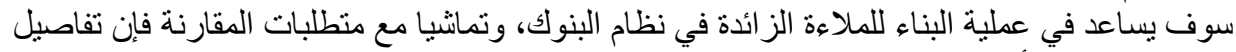
هذا المؤشر لا بد أن يكون متفق عليها دوليا بما في ذللك المعالجات المحاسية المبانة.

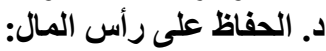

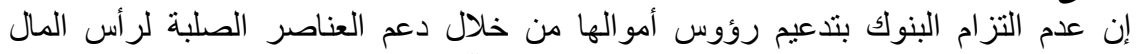

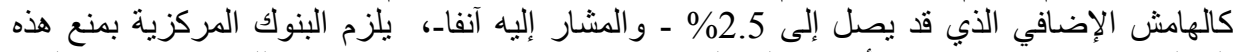

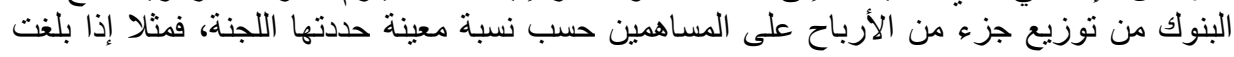


العناصر الصلبة لبنك ما 5.20\% من الأصول المرجحة (4.5\% القانونية + 0.7\% هامش إضافي)، فإنه

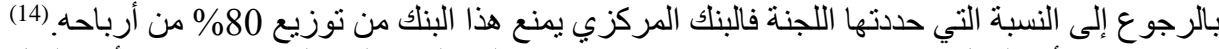

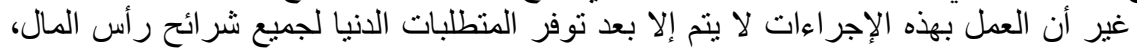

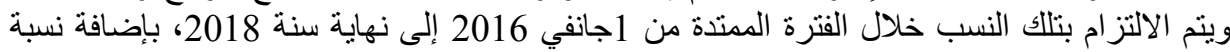

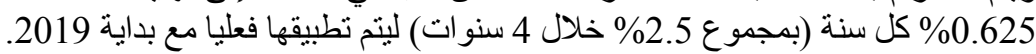

ه. توصيات البنوك ذات الحجم الكبير:

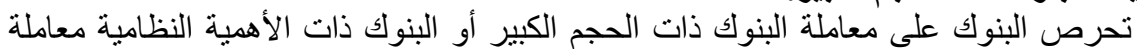

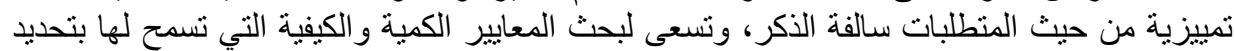

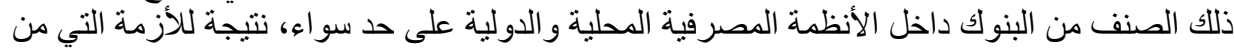

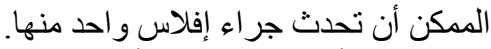

و. حواجز رأس المال ضد التأثير الحلقي:

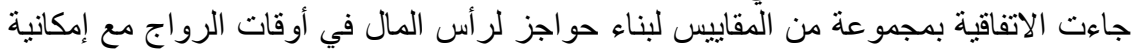

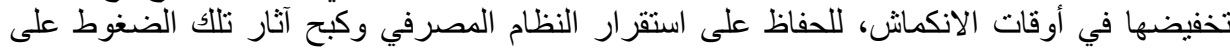

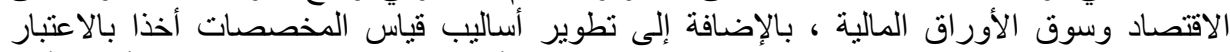

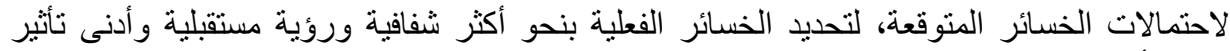

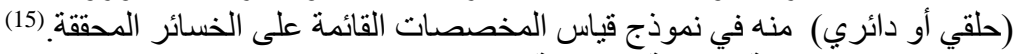

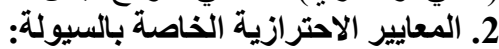

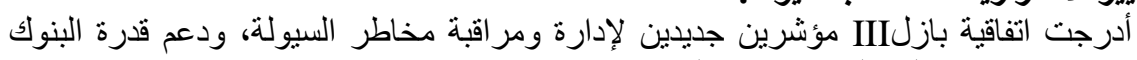

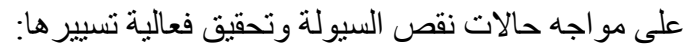
أ. معيار السيولة للأجل القصير (نسبة تغطية السيولية):

تقدر نسبة السيولة قصيرة الأجل باحتساب الأصولة شديدة السية السيولة ـالمتاحةـ إلى صافي التدفقات

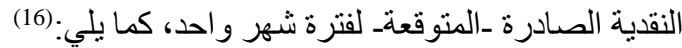

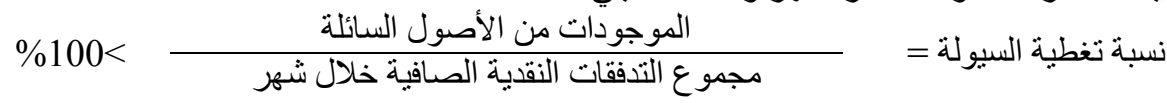

$$
\text { حيث أن: }
$$

- ـ - الموجودات من الأصول السائلة: تمثل الأصول ذات الجودة العالية، التي تحافظ على

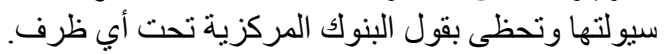

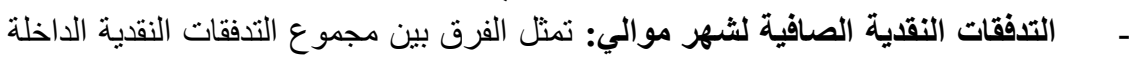

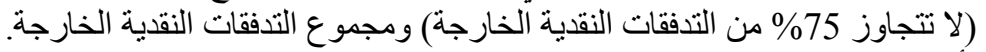

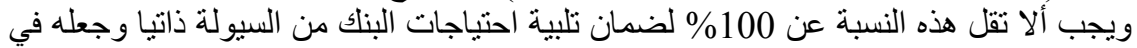

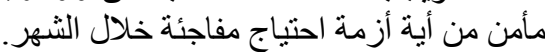

ب. معيار السيولة في المدى الطويل (نسبة السيولة الهيكية الهيكليةـ طويلة الأجل):

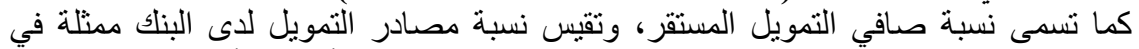

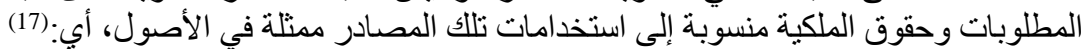

$$
\% 100<
$$

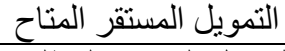

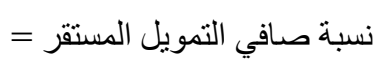

ـالتمويل المستقر المتاح: يمثل عناصر المطاليب أو الخصوم (الأموال الصافية، الودائع

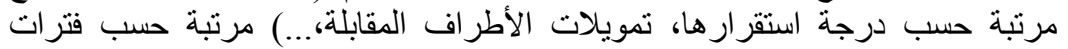

الاستحقاق. 
ـالتمويل المستقر المطلوب: يشمل عناصر أصول الميزانية، وعناصر محددة خارج الميزانية،

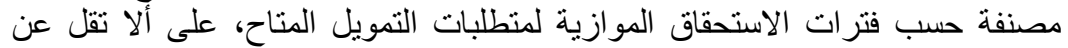

$\% 100$

تهدف هذه النسبة إلى توفير البنوك لموارد سيولة مستقرة لدعم تمويل أصولها على المديين

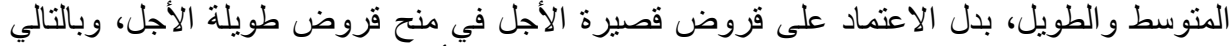

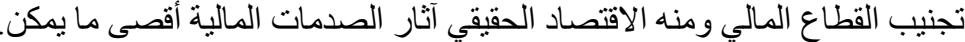

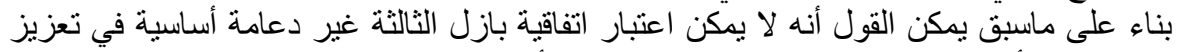

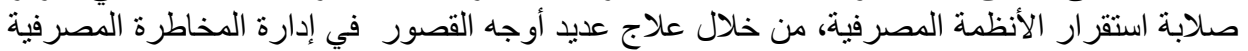

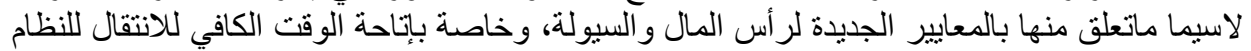
الجديد عن طريق التطبيق التدريجي للمعايير الاحترازية إلى غاية 2019.

\section{المحور الثاني: واقع التزام البنوك الجزائرية بالمعايير الاحترازية الدولية}

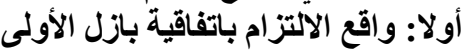

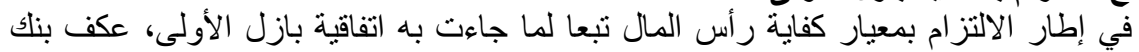

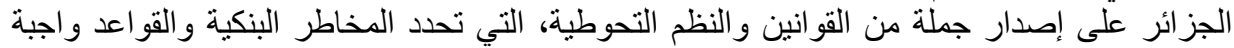

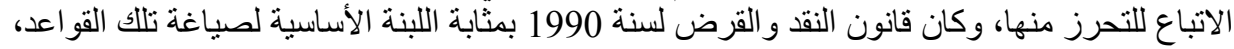

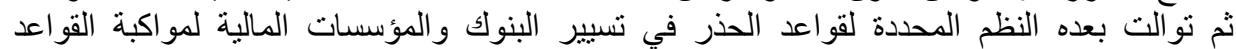

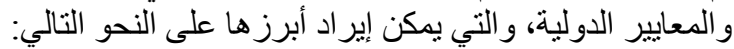

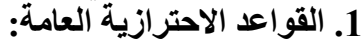

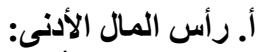

يمثل رأس المال بالنسبة للبنك الدعامة الأساسية لمجابهة المخاطر، والضمان الأنسان الأساسي في

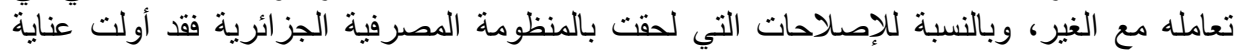

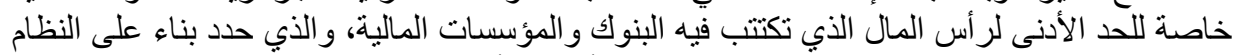

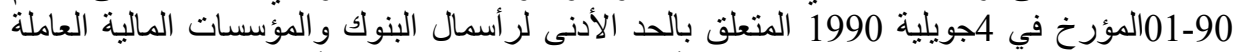

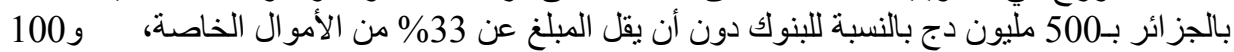

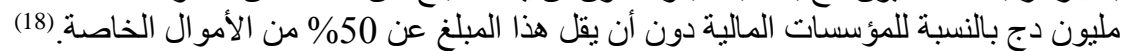

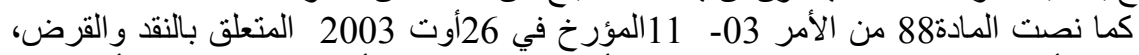
على ضرورة أن يتوفر للبنوك و المؤسسات المالية رأسمال محرر جزئين أو كليا ليا يعادل على الأقل المبلغ

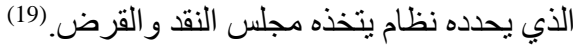

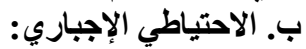

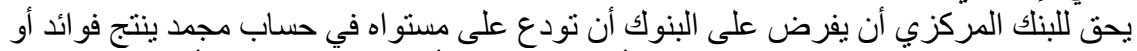

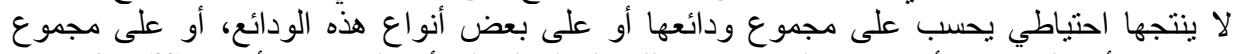

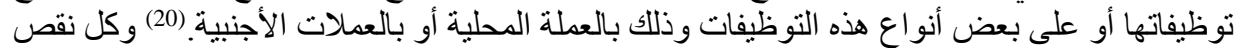

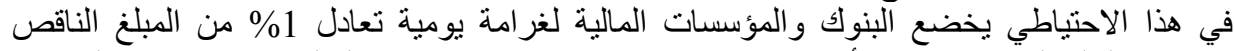

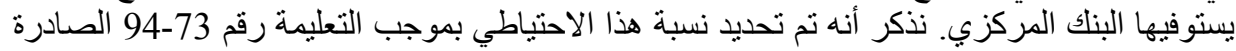

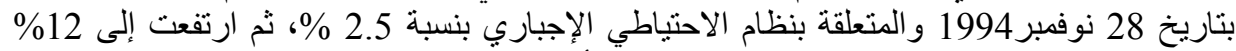

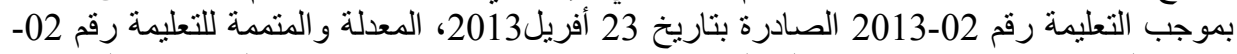

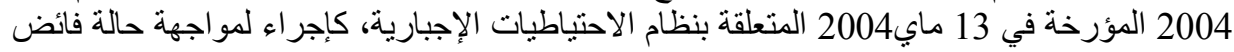

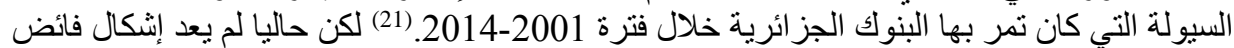

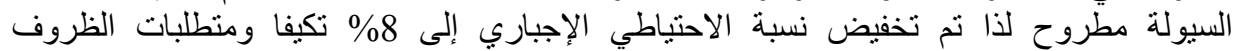
الاقتصادية، وذلك بموجب التعليمة رقم 01-08 المؤرخة في 10 جالإنفي 2018 المتعلقة بنظام 


\section{ج. متابعة الالتزامات وضمان الودائع:}

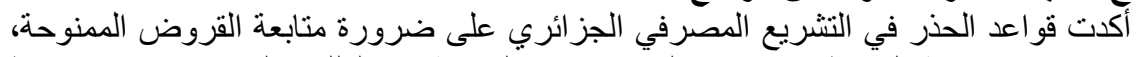

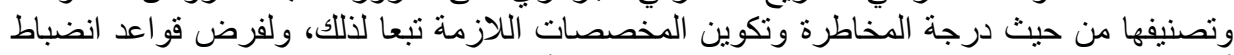

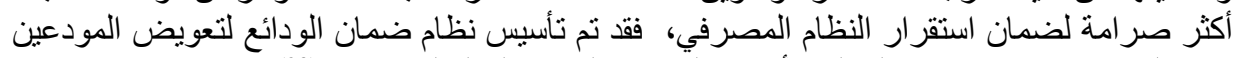

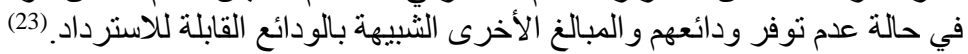

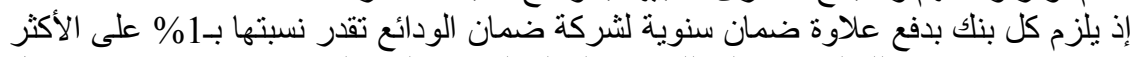

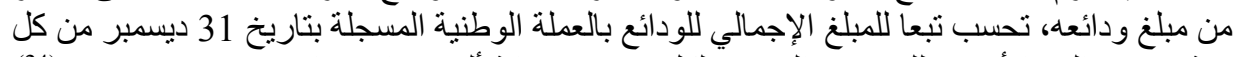

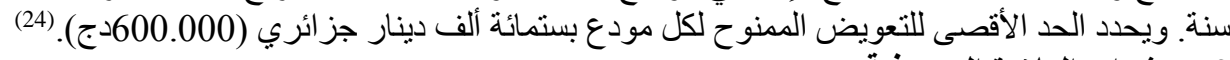

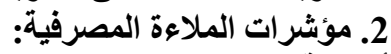

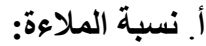

أولى التشريع المصرفي الجزائري عناية خاصة للملاءة المصرفية على اعتبار أنها تمثل أساس

السلامة المصرفية، وفي إطار ذلك ألزم النظام 91-09 المؤرخ فئ في 14 14أوت

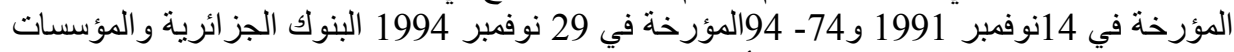

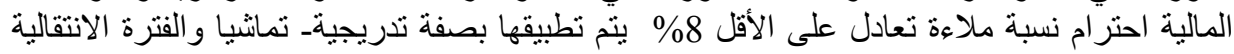

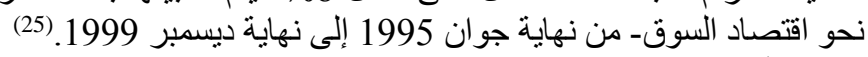
أوجبت قو اعد الحذر تنويع مخاطر العملاء وتفادي تركيز ها مع عميل واحد أو نفس المجموعة

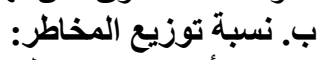

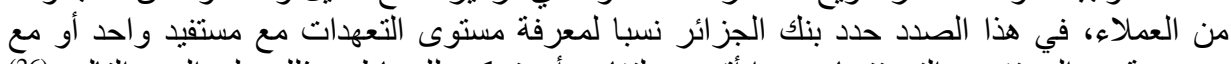

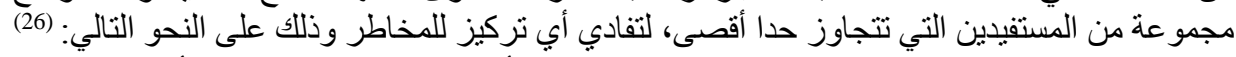

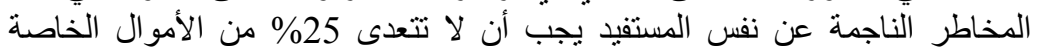

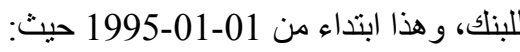

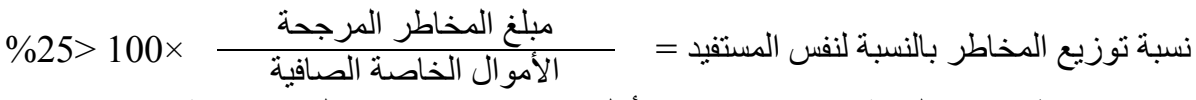

وتم تطبيق هذه النسبة تدريجيا ابتداء من أول جانفي 1992 بما يعادل 40\%، ثم 30\%

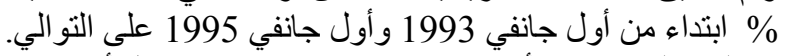

وكل تجاوز لهذه النسب لا بد أن يعقبه مباشرة تكوين تغطية تمثل أضعاف معدلات الماتل الماءة المالية.

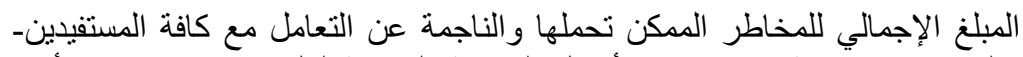

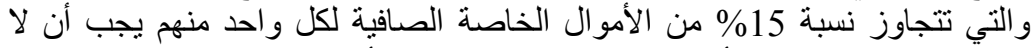

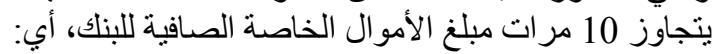

$$
\text { مبلغ المخاطر المحتملة لكل المستفيدين }
$$

ثانيا: محاولات مواكبة القواعد الاحترازية لاتفاقية بازل الثانية:

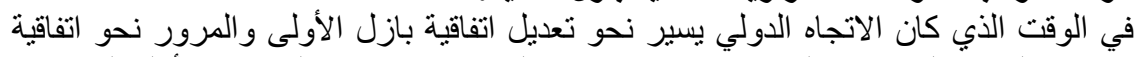

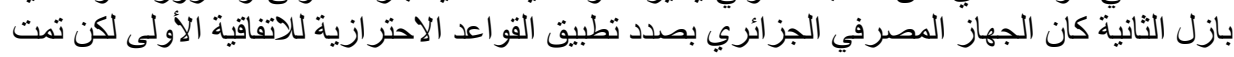

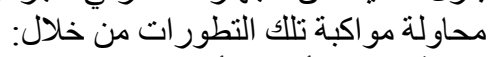
1. 1فع الحد الأدنى لرأس المال:

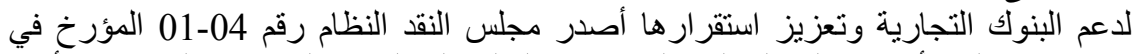

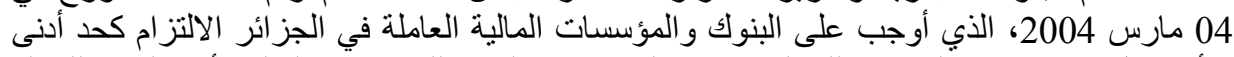

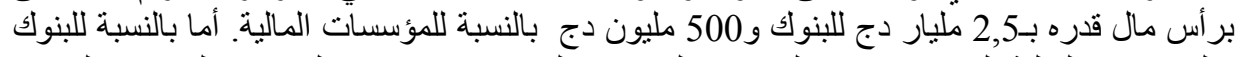

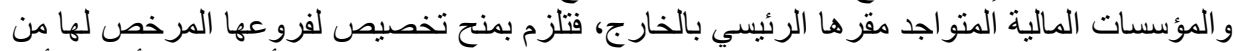

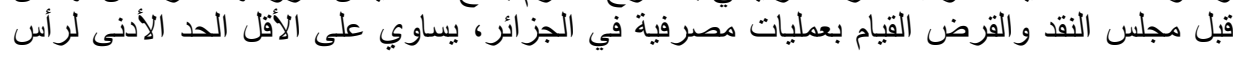


المال المطلوب لتأسيس البنوك والمؤسسات المالية الخاضعة للقانون الجزائري والمنتمية لذات (27) الصنف (الصال

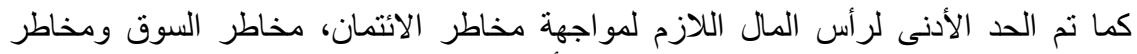

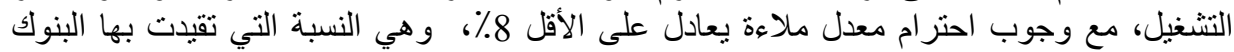
الجز ائرية بل وتجاوز ها بعضها ابتداء من سنة 2003.

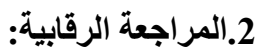

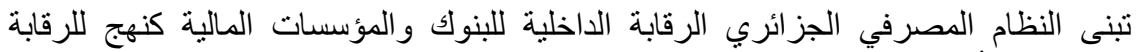

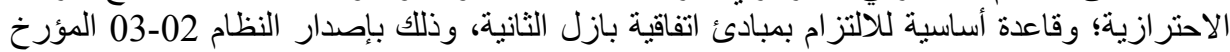

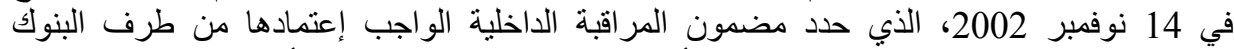

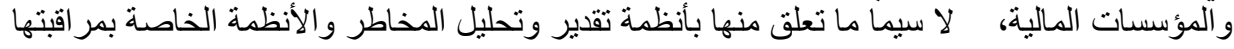

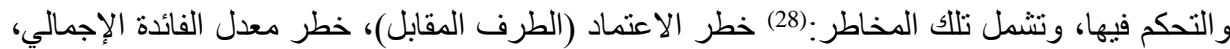

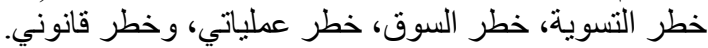

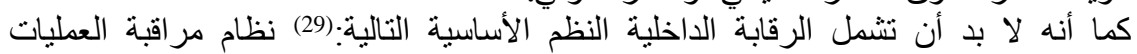

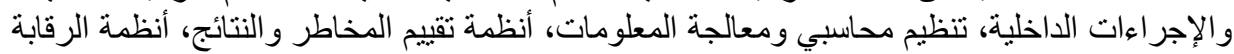

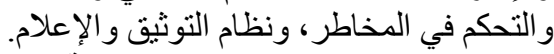

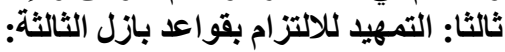

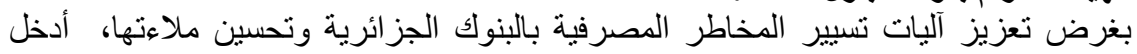

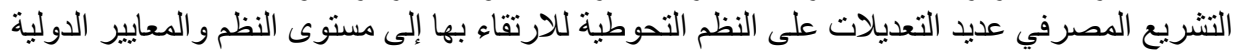

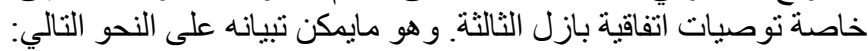

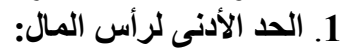

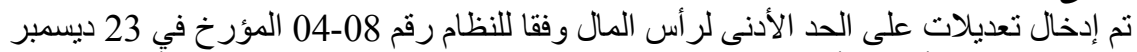

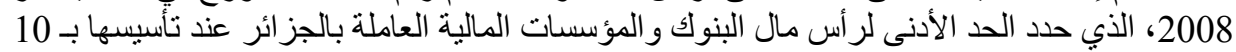

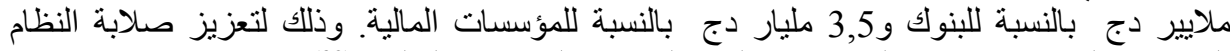
المصرفي الجز ائرب وتهيئته لمو اكبة منطلبات الصناعة المصائة المصرفية العالمية. (30)

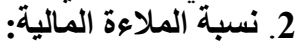

جاء النظام 14-014، المؤرخ في 16 فيفرية2014 ليعدل هذه النسبة وتصير 9,5\% بدلا من

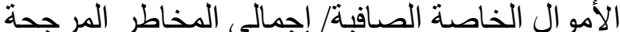

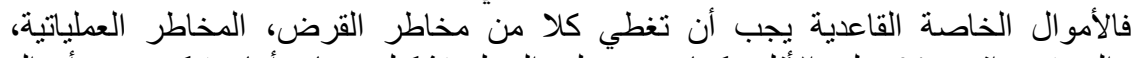

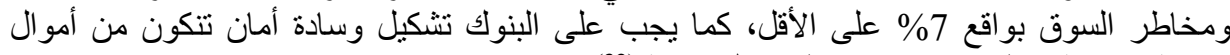

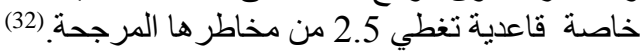

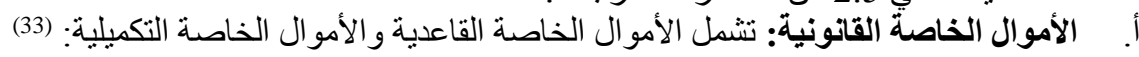

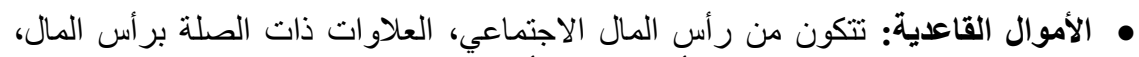

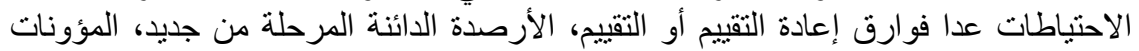

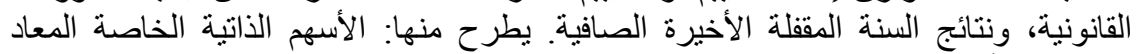

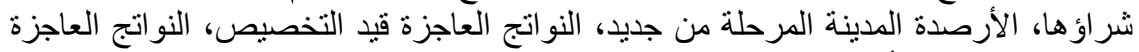

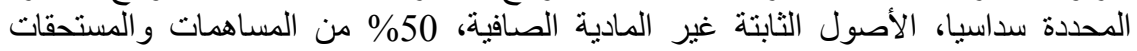

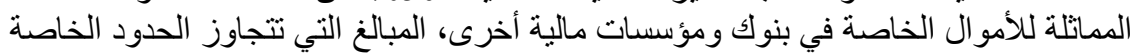

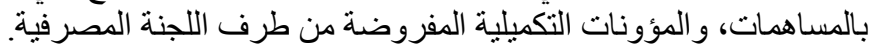

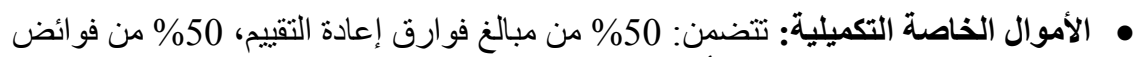
القيم الكامنة المستحقة عن تقييم الأصول المتاحة للييع، مؤونات لتغطية المخاطر المصرفي، 


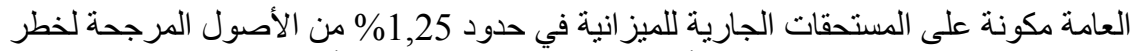

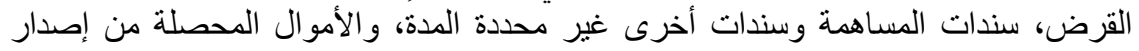

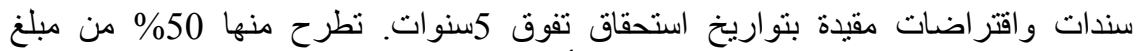

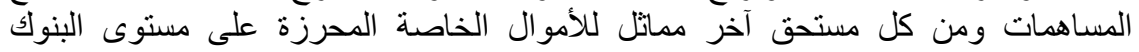
و المؤسسات المالية. ب. المخاطر المرجحة: تشمل مخاطر القرض، المخاطر العملياتية ومخاطر السوق:

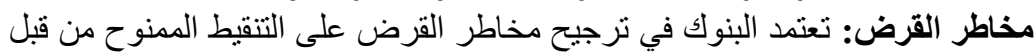

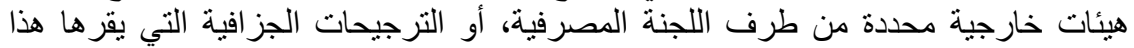

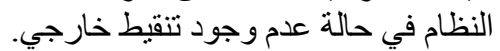

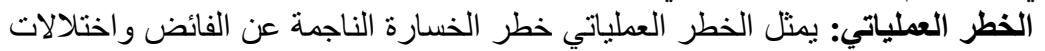

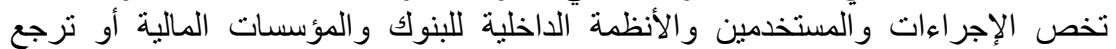

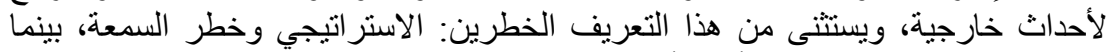

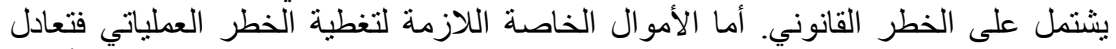
متطلبات 15\% من متوسط صافي النواتج البنكية الصافية الإيجابية السنوية للسنوات الات الأخيرة الثلاث.

خطر السوق: يشمل خطر السوق خطر الصرف، وخطر الوضعية على محفظة التداول

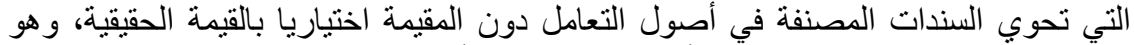

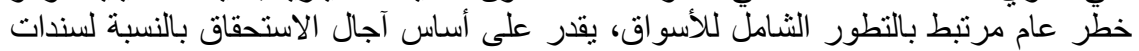

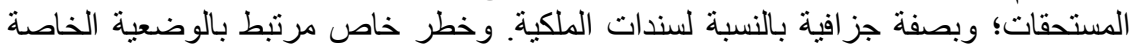

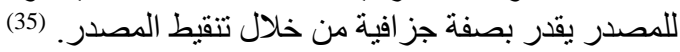

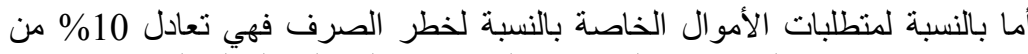

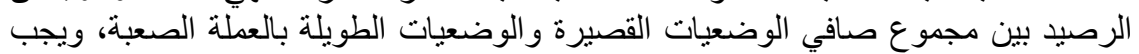

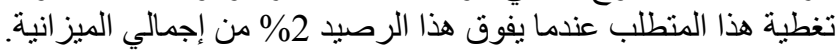

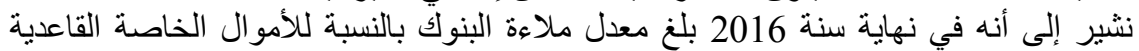

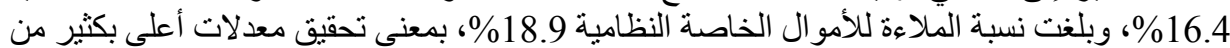

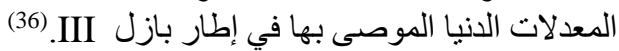

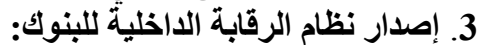

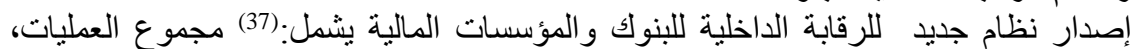

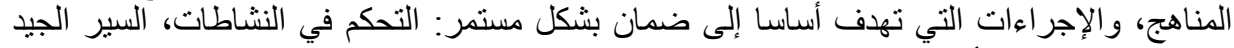

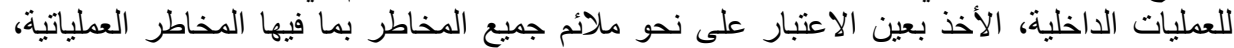

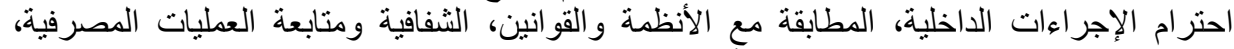

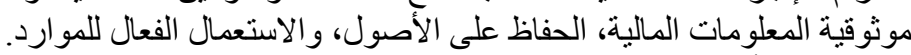

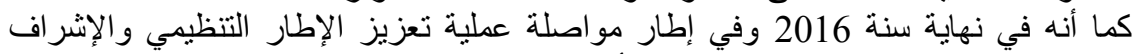

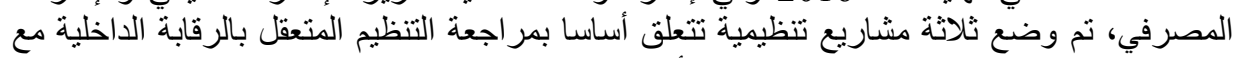

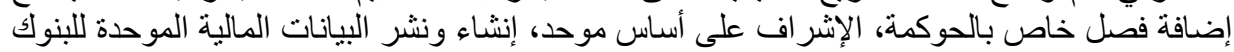

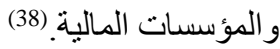

4. فرض نسب السيولة:

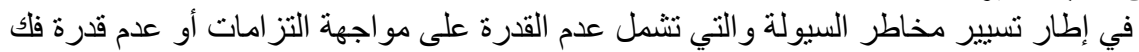
أو تعويض وضعية نظر الحالة السوق، وذلك في أجل محدد وبتكلفة معقولة، فإنه يتوجب الفي على نلى 
الحبازة الفعلية والدائمة للسيولة الكافية لمواجهة التزاماتها عند استحقاق أدائها، بو اسطة مخزون من الأصول السائلة.

تأمين تتويع كاف لمصادر التمويل حسب المبالغ وآجال الاستحقاق والطرف

اختبار دوريا إمكانيات الإقراض المتاحة لها لاى الأطراف المقابلة سواء في

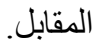

الظروف العادية أو في حالة أزمة.

فالبنوك ملزمة بتقديم معامل سيولة دائم يسمى "المعامل الأدنى للسيولة"، مساو على الأقل

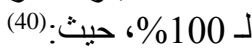

المعامل الأدنى للسيولة الأصول السائلة قصيرة الأجل +التزامات التمويل من البنوك

$\% 100 \leq$

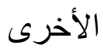

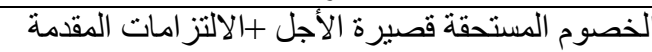

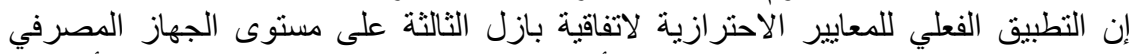

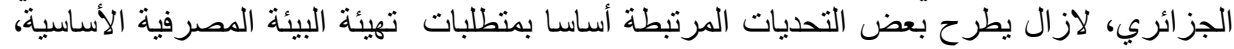

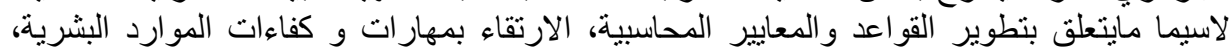

تحسين جودة الأنشطة و الخدمات المصرفية.

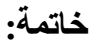

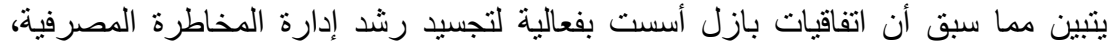
استتادا إلى قو اعد أساسية تفرض انضباطية مثلى يهذف التقات التقد بها إلى تحقيق استقر ار النظام المالي في

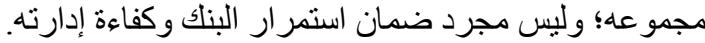

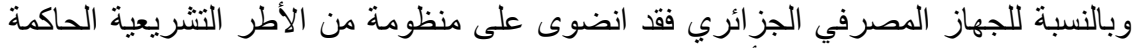

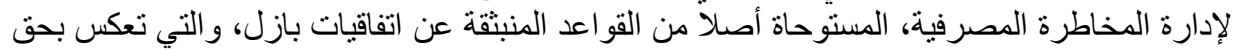

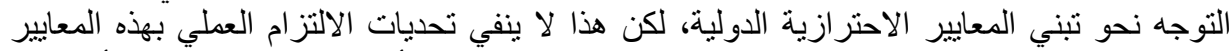

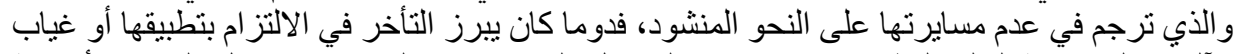

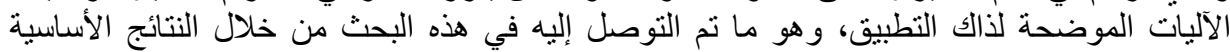

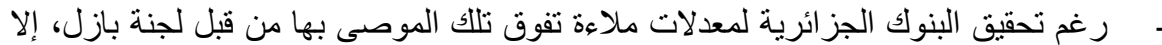

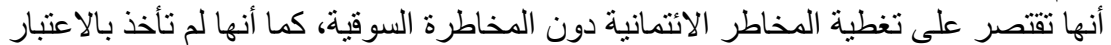
المخاطر التشغيلية والتي تعتبر إحدى الإضافات الإنية الأساسية لاتفاقية بازل الثانية الثانية.

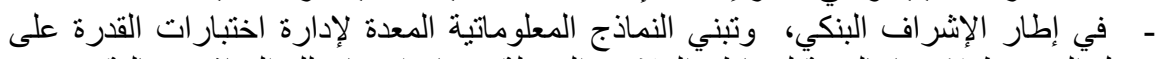

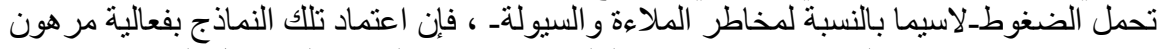

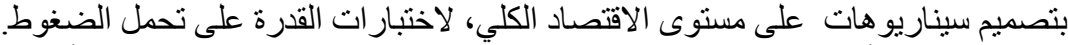

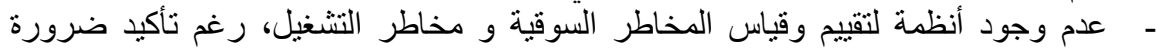

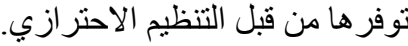

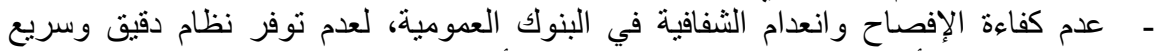

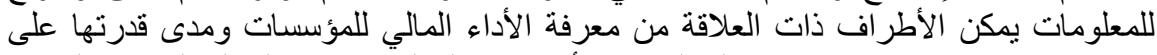

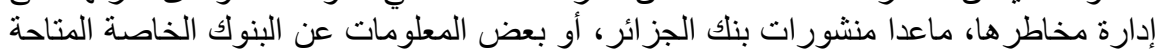

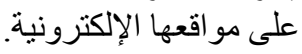




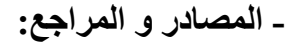

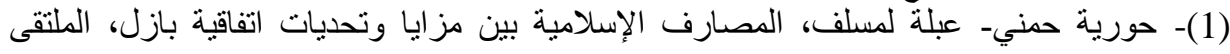

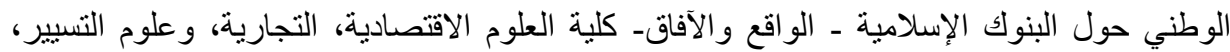

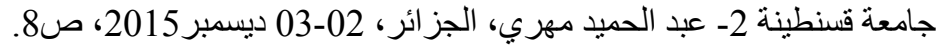
(2)-حسين جو اد كاظم، منذر حبار داغر، القطاع المصرفي في العراق ومعوقات التهات التكيف مع معايير

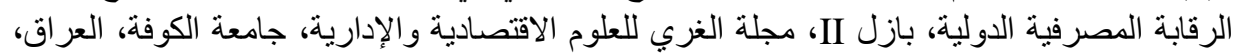

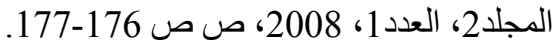
(3)- سليمان ناصر ، النظام المصرفي الجزائري واتفاقيات بازل، مجلة العلوم الاقتصادية و علوم

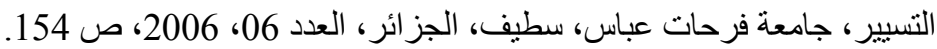

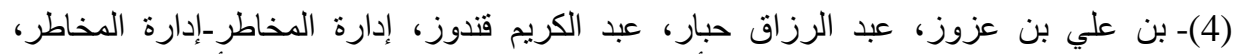

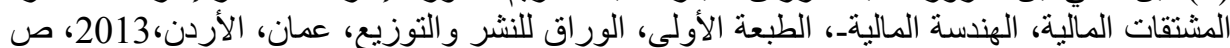

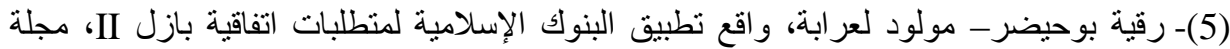

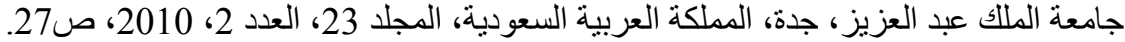
(6)- Arnaud de servign, Ivan Zelenko, le risque de crédit face à la crise, $4^{\mathrm{e}}$ édition, Dunod, Paris, 2016, P261.

(7)- فاطمة الزهراء زغاثو - فوزي غربي، إدارة المخاطر في عقود التمويل الإسلامية، الملتقى الوطني حول المصنارف الإسلامية ـ واقع و آفاق، 2-3 ديسمبر 2015، جامعة قسنطينة2- عبد الحميد

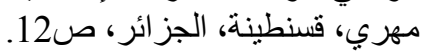
(8)

(9)- Abdelkader Beltas, La titrisation- Instrument efficace pour la gestion du risque du crédit bancaire, légende, Algérie, 2007, P149.

(10)- John hull, Gestion des risques et institution financière, la source d'or, France, 2007, p170.

(11)-زهير غراية- عبد القادر بريش، مقررات بازل III ودورها في تحقيق مبادئ الحوكمة وتعزيز

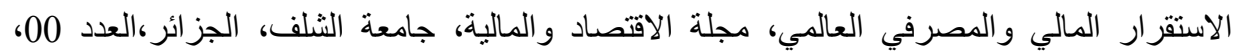

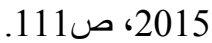

(12)-محمد رضا بوسنة، الأزمات المالية العالمية ومعيار بازلIII)، مجلة أبحاث اقتصادية وإدارية،

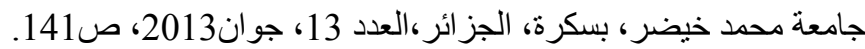

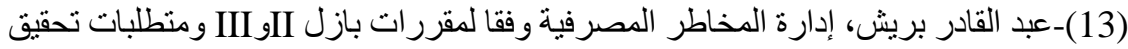

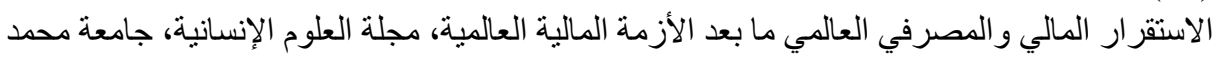

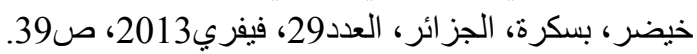

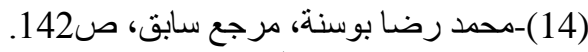

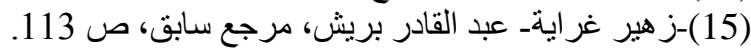
(16)- Salwa Fariji, Vincent Boisbourdain, Crise de liquidité, Pilotage du LCR ou du risque- de liquidité, Revue d'opus finance, Paris, $N^{\circ} 1$, Decembre 2012 , $\mathrm{p} 25$.

(17)-Op. cit, p25. 
(18)-المادة 1من النظام رقم 90-01 المؤرخ في 04 جويلية 1990، المتعلق بالد الأدنى لرأسمال

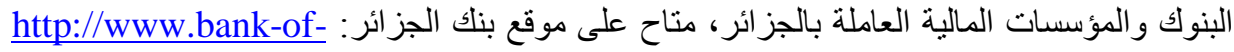

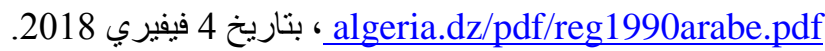

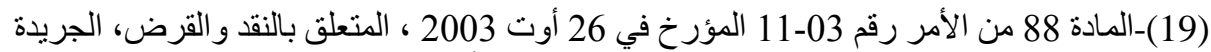

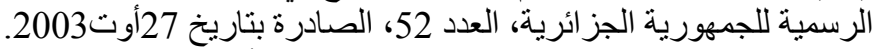

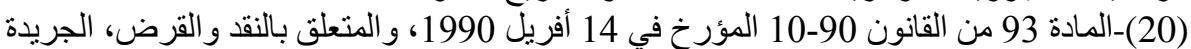

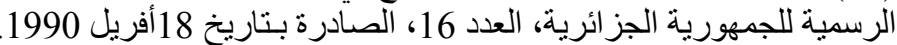
(21)-موقع بنك الجز ائر: http://www.bank-of-algeria.dz/html/legist2013.htm ، بتاريخ ائريل 12 ماي 2018 موفع

(22)-موقع بنك الجزائر: http://www.bank-of-algeria.dz/pdf/instructions2018.pdf

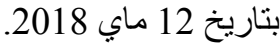
(23)-المادة 3من النظام 04-03 المؤرخ في 4مارس 2004، 2004،المتعلق بنظام ضمان التبان الودائع المصرفية،

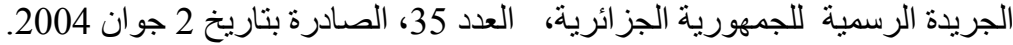

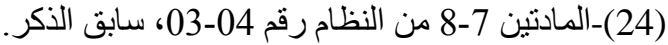

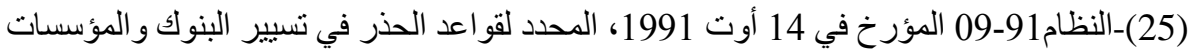

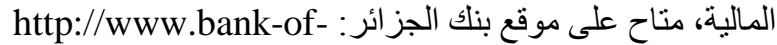

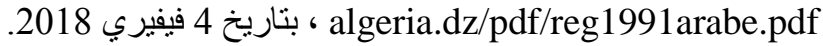
-Instruction $\mathrm{n}^{\circ} 74-94$ du 29 novembre 1994 relative a la fixation des règles prudentielles de gestion des banques et établissements financiers, Sur cite d'internet: http://www.bank-of-algeria.dz/html/legist10_5.htm ,vue le 4 Février 2018.

(26)-Instruction $\mathrm{n}^{\circ}$ 74-94 du29 novembre 1994, Op. cit. (27)-المواد3،2،1 من النظام 04-01 المؤرخ في 04 مارس 2004، المتعلق بالحد الأدنى لرأسمال

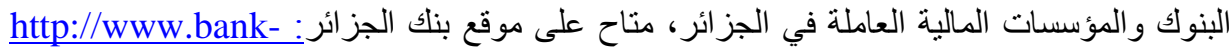

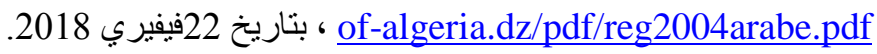

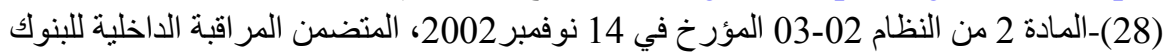

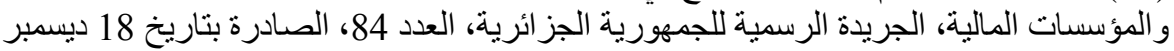
.2002

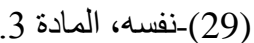
(30)_المادة 2 من النظام 04-08 المؤرخ في 23 ديسمبر 2008، المتعلق بر أسمال البنوك و المؤسسات

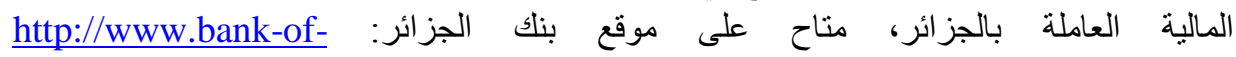

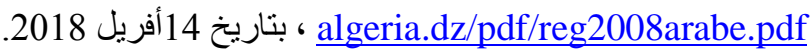

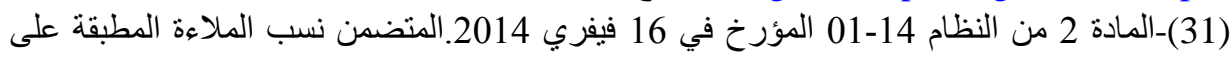

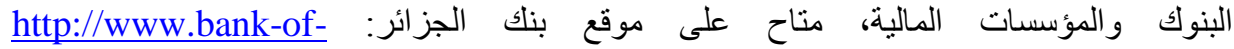

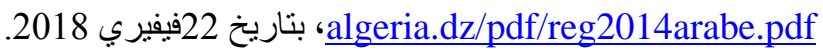


(36)- التقرير السنوي لبنك الجزائر لسنة 2016، التطور الاقتصادي و النقدي للجز ائر، ص 96، متاح

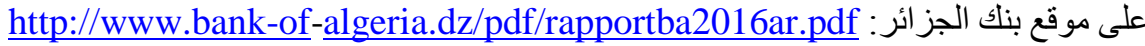

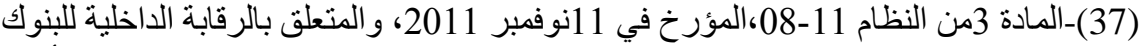

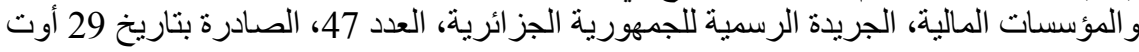
2012

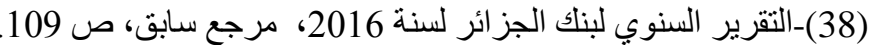

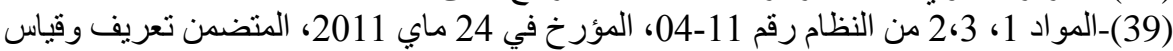
وتسيير ورقابة خطر السيولة، الجريدة الرسمية للجمهورية الجزائرية، العديد 54، 54، الصادرة بتاريخ

2أكتوبر 2011. (40)-نفسه، المادة 3. 